\title{
Remotely sensed latent heat fluxes for model error diagnosis:
} a case study

\author{
J. M. Schuurmans ${ }^{1,{ }^{*}}$, F. C. van Geer ${ }^{2}$, and M. F. P. Bierkens ${ }^{1,2}$ \\ ${ }^{1}$ Department of Physical Geography, Faculty of Geosciences, Utrecht University, P.O. Box 80115, \\ 3508 TC Utrecht, The Netherlands \\ ${ }^{2}$ Deltares, P.O. Box 80015, 3508 TA Utrecht, The Netherlands \\ *now at: DHV B.V., P.O. Box 1132, 3800 BC Amersfoort, The Netherlands
}

Received: 22 June 2010 - Published in Hydrol. Earth Syst. Sci. Discuss.: 25 August 2010

Revised: 12 February 2011 - Accepted: 15 February 2011 - Published: 4 March 2011

\begin{abstract}
This study shows that remotely sensed $\mathrm{ET}_{\text {act }}$ is useful in hydrological modelling for the procedure of model calibration and shows it potential to update soil moisture predictions. Comparison of modeled and remotely sensed $\mathrm{ET}_{\mathrm{act}}$ together with the outcomes of our data assimilation procedure points out potential model errors, both conceptual and flux-related. Assimilation of remotely sensed $\mathrm{ET}_{\mathrm{act}}$ results in a realistic spatial adjustment of soil moisture, except for the area where the model suffers from conceptual errors (forest with deep groundwater levels). By using operational (i.e. available for community in practice) data and models we aim to show the potential and limitations of using remotely sensed $\mathrm{ET}_{\text {act }}$ in the practice of hydrological modelling. We use satellite data of both ASTER and MODIS for the same two days in the summer of 2006 that, in association with the Surface Energy Balance Algorithm for Land (SEBAL), provides us the spatial distribution of daily $\mathrm{ET}_{\mathrm{act}}$. The model, used by the local water board, is a physically based distributed hydrological model of a small catchment $\left(70 \mathrm{~km}^{2}\right)$ in The Netherlands that simulates the water flow in both the unsaturated and saturated zone. Model outcomes of $\mathrm{ET}_{\text {act }}$ show values that are at least $20 \%$ lower than those estimated by SEBAL, which is due to the fact that different evapotranspiration methods are used. The spatial pattern of $\mathrm{ET}_{\text {act }}$ from the hydrological model resembles the soil map, whereas the $\mathrm{ET}_{\mathrm{act}}$ from SEBAL resembles the land use map. As both ASTER and MODIS images were available for the same days, this study provides an opportunity to compare the worth of these two satellite sources. It is shown that,
\end{abstract}

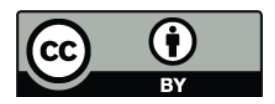

Correspondence to: J. M. Schuurmans (hanneke.schuurmans@dhv.com) although ASTER provides better insight in the spatial distribution of $\mathrm{ET}_{\text {act }}$ due to its higher spatial resolution than MODIS, they appeared in this study just as useful.

\section{Introduction}

Accurate prediction of spatially-distributed soil moisture with high spatial resolution is helpful for optimizing irrigation application, hydrological drought forecasting and the assessment of catchment wetness for flood control. Physically based spatial distributed hydrological models have the potential to provide this insight. As more spatially-distributed information about land surface characteristics becomes available and computer capacity increases, the distributed hydrological models are also developed at higher spatial resolutions (Bergström and Graham, 1998). Potentially these high resolution models can give us insight into the hydrological processes in more detail. However, the possibilities to calibrate those models or to validate the accuracy of the model predictions is often limited by the number of (distributed) measurement data. In most cases only observations of groundwater are available at a few points, while in-situ measurements of soil moisture are rare. Discharge data, if available, give only integrated hydrological information of an area. A data source that does provide spatially-distributed soil moisture data, or soil moisture related data, are satellites from which latent heat fluxes can be derived (Kustas and Norman, 1996). This paper focuses on satellites that are equipped with thermal bands. Models that are based on the surface energy balance like for instance SEBS ( $\mathrm{Su}$, 2002) and SEBAL (Allen et al., 2001; Bastiaanssen, 1995;

Published by Copernicus Publications on behalf of the European Geosciences Union. 


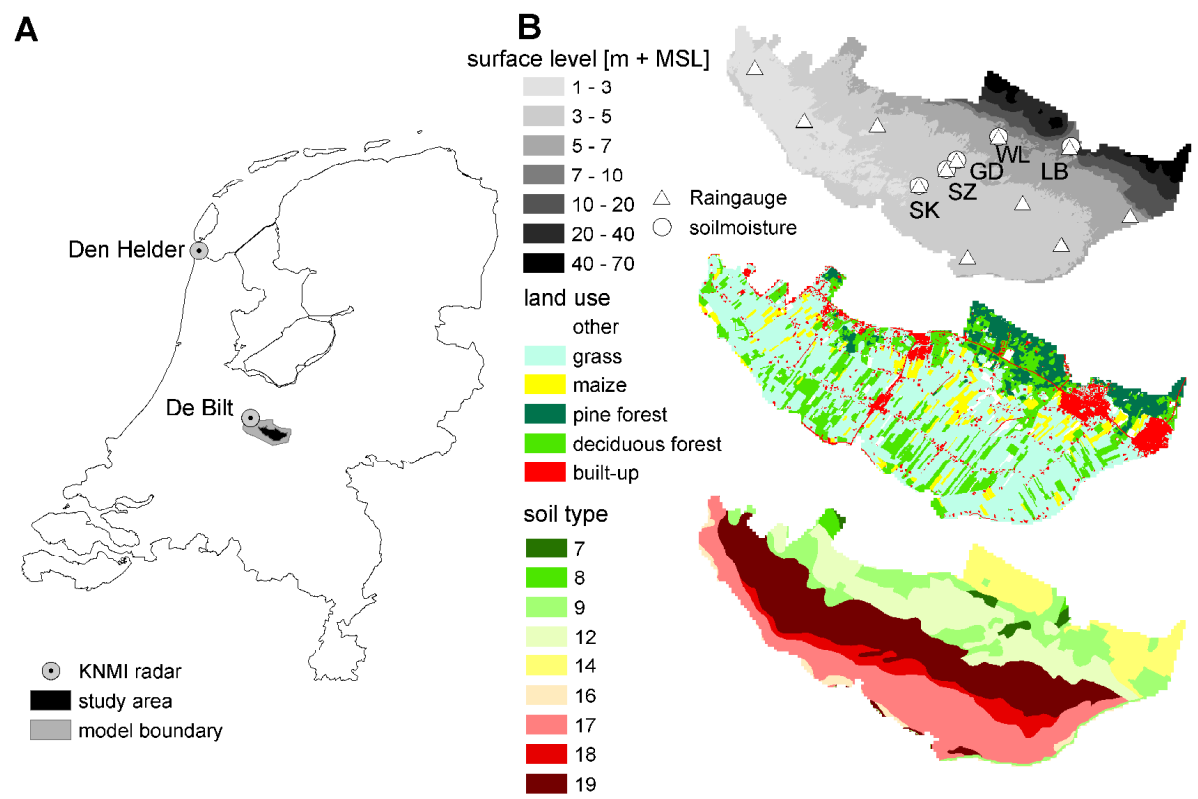

Fig. 1. (A) Location of the study area within the Netherlands. (B) Surface level, land use and soil types within the study area.

Bastiaanssen et al., 2005) can convert thermal band satellite images into images of actual evapotranspiration. These products can be used for model verification or model calibration, as was demonstrated by Immerzeel and Droogers (2008).

The purpose of this study is to answer the question: "Can remotely sensed latent heat fluxes (i.e. actual evapotranspiration, $\mathrm{ET}_{\mathrm{act}}$ ) improve the accuracy of the prediction of spatially-distributed soil moisture as made by a distributed hydrological model?". We will answer this question by using a real case study, by which we aim to show the potential and limitation of our approach for hydrological model validation in practice. Outcomes of an operational physically based distributed $(25 \mathrm{~m} \times 25 \mathrm{~m})$ hydrological model of a small catchment $\left(70 \mathrm{~km}^{2}\right)$ in The Netherlands are compared with satellite (both ASTER and MODIS) based $\mathrm{ET}_{\mathrm{act}}$ for the same two days in summer 2006. The Surface Energy Balance for Land (SEBAL) is used in this study to process the satellite data. We use an operational physically based distributed $(25 \mathrm{~m} \times 25 \mathrm{~m})$ hydrological model that simulates the water flow in both the unsaturated and saturated zone, from now on referred to as MetaSWAP. In order to improve the model predictions of soil moisture we assimilate $\mathrm{ET}_{\text {act }}$ into our model, using a statistical correction method that weighs the error of both hydrological model based and satellite based $\mathrm{ET}_{\text {act. }}$. In an earlier study we already assimilated $\mathrm{ET}_{\text {act }}$ into another but conceptual similar spatially-distributed hydrological model (Schuurmans et al., 2003). Although promising, the results of this former study remained unverified, as was pointed out by Pipunic et al. (2008). In this study we use soil moisture measurements from 5 locations within the catchment, as well as validation data of SEBAL from The Netherlands, in order to get insight into the error of both hydrological model based and satellite based $\mathrm{ET}_{\text {act }}$ rather then using different (unknown) weighing factors as we did in our previous study. As both an ASTER and MODIS image were available for the two days ( 8 June and 17 July), this study also provides an excellent opportunity to compare the worth of these two satellite sources.

The remainder of this paper is organized as follows. Section 2 gives a description of the study area. Section 3 introduces the hydrological model (MetaSWAP) and the data that is used in this study, which includes the rainfall, evapotranspiration, soil moisture and groundwater. This section also gives the MetaSWAP outcomes of these variables. Section 4 deals with the data assimilation method; first the method itself followed by its parameterization. Section 5 shows the results of the spatially distributed updated soil moisture and discusses the outcomes. Finally the main conclusions are drawn in Sect. 6 and an outlook for improvement of the presented method is given.

\section{Study area}

Our study area is called the "Langbroekerwetering" and lies in the central part of The Netherlands (Fig. 1a). The Langbroekerwetering $\left(70 \mathrm{~km}^{2}\right)$ is located along the rim of the Holocene Rhine-Meuse delta (Berendsen and Stouthamer, 2000), which onlaps cover sands and sandur outwash deposits in front of a Saalian ice-pushed ridge (Busschers et al., 2007). Figure $1 \mathrm{~b}$ shows the elevation together with the location of the rain gauges and the soil moisture measurements, land use and soil types of the Langbroekerwetering. For a description of the soil types we refer to Table 1. At the 
Table 1. Description of soil types within study area (Wösten et al., 1988) as well as the indexed error zone (see Sect. 4.2).

\begin{tabular}{clc}
\hline Soil unit & Description & Error zone \\
\hline 7 & Drift sand & 5 \\
8 & Podzol in loam poor fine sand & 3 \\
9 & Podzol in loamy fine sand & 3 \\
12 & Enkeerd in loamy fine sand & 4 \\
14 & Podzol in coarse sand & 5 \\
16 & Light clay & 2 \\
17 & Clay with heavy clay layers & 1 \\
18 & Clay on peat & 1 \\
19 & Clay on sand & 2 \\
\hline
\end{tabular}

higher elevations with coarse sand forest dominates the area, while in the lower area grassland dominates. Within the area some small villages (built-up area) are located. The land use map is derived from the Dutch national land-cover database LGN (Oort et al., 2004; De Wit and Clevers, 2004).

\section{Data}

\subsection{Hydrological model}

The model used in this study is a coupled groundwater and unsaturated zone model, referred to as MetaSWAP from now on. The groundwater model is based on the MODFLOW model code (McDonald and Harbaugh, 1988). The unsaturated zone model, is a quasi steady-state model that uses a sequence of steady-state water content profiles for dynamic simulation (Van Walsum and Groenendijk, 2008). The steady-state water content profiles were obtained by running a steady-state version of the SWAP model (Van Dam, 2000) off-line. The model area is divided into SVAT-units (Soil Vegetation Atmosphere Transfer), which are smaller or equal to the size of the MODFLOW cell. One MODFLOW cell can be coupled to several SVAT-units. The SVAT-units form parallel vertical columns, which are divided into a root zone and a subsoil layer. MetaSWAP distinguishes 21 different soil types. For each soil type the model has predefined sublayers with corresponding soil physical parameters, the Van Genuchten parameters (Van Genuchten, 1980), to be able to convert pressure head to soil moisture content. In the unsaturated part of the hydrological model only vertical flow according to Richards' Equation is taken into account. All lateral exchanges are assumed to take place in the saturated zone. The thickness of the root zone is user specified. In our model, the size of the MODFLOW cells is $100 \mathrm{~m} \times 100 \mathrm{~m}$. The SVAT-units have a resolution of $25 \mathrm{~m} \times 25 \mathrm{~m}$ inside the study area and $100 \mathrm{~m} \times 100 \mathrm{~m}$ outside the study area, within the model boundaries (Fig. 1a).

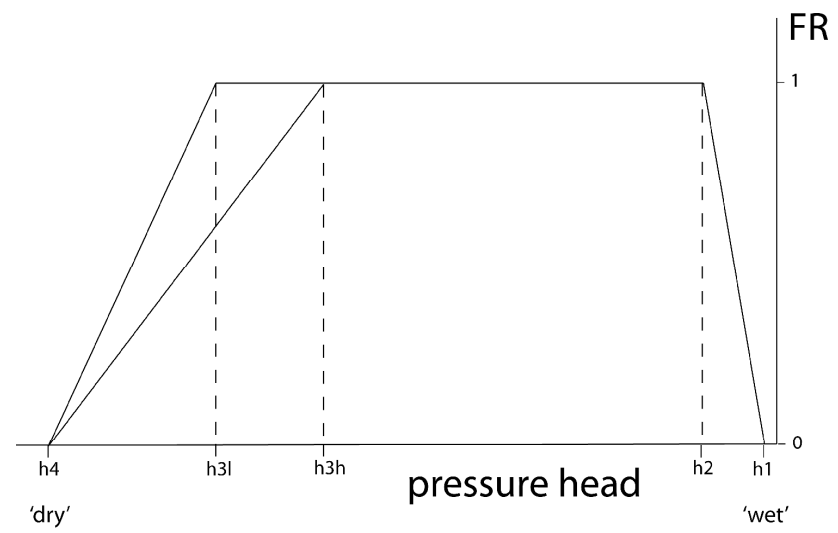

Fig. 2. Feddes reduction factor $(F R)$ as function of pressure head: between $h_{1}$ and $h_{2}$ there is reduction of potential evaporation because of oxygen deficit of roots. Between $h_{2}$ and $h_{3}$. $\mathrm{ET}_{\text {act }}$ equals $\mathrm{ET}_{\text {pot }}$. Between $h_{3}\left(h_{3} l\right.$ and $h_{3} h$ correspond to resp. $\quad \mathrm{ET}_{\text {pot }}=1 \mathrm{mmd}^{-1}$ and $\mathrm{ET}_{\text {pot }}=5 \mathrm{mmd}^{-1}$ ) and $h_{4}$ there is evapotranspiration reduction due to water deficit. After Feddes et al. (1978).

\subsection{Rainfall}

The daily rainfall fields ( $25 \mathrm{~m}$ by $25 \mathrm{~m}$ ) that are used as input for MetaSWAP are a combination of meteorological radar (Fig. 1a) and rain gauges within and closely around the model area. The interpolation method used is a geostatistical method that combines radar estimates with rain gauge observations. The method makes use of collocated cokriging and is explained in more detail in Schuurmans et al. (2007).

\subsection{Evapotranspiration}

MetaSWAP uses Makkink (De Bruin, 1987; Makkink, 1957; Winter et al., 1995), which is comparable to the internationally better known Priestley-Taylor method, reference evapotranspiration $\left(\mathrm{ET}_{\mathrm{ref}}\right)$ as input. The Royal Netherlands Meteorological Institute (KNMI) delivered daily values of ETref, which we assumed to be spatially uniform over the model area. The potential evapotranspiration $\left(\mathrm{ET}_{\mathrm{pot}}\right)$ is calculated by multiplying ETref with a crop factor, which is related to the land use type and can vary throughout the season (Feddes, 1987). The actual evapotranspiration $\left(\mathrm{ET}_{\mathrm{act}}\right)$ is equal or a fraction of $\mathrm{ET}_{\text {pot }}$ depending on the soil moisture conditions and the land use type (Eq. 1)

$\mathrm{ET}_{\text {act }}=F R \cdot \mathrm{ET}_{\text {pot }}$

in which $F R$ is the called the Feddes reduction factor from now on. Figure 2 shows the so called Feddes-reduction curve (Feddes et al., 1978), which gives the relation between $F R$ and the soil moisture pressure head. The values of the critical pressure heads $\left(h_{1}-h_{4}\right)$ can be defined for each land use type. It must be noted that the choice of these values is one of the uncertainty sources in the model. 

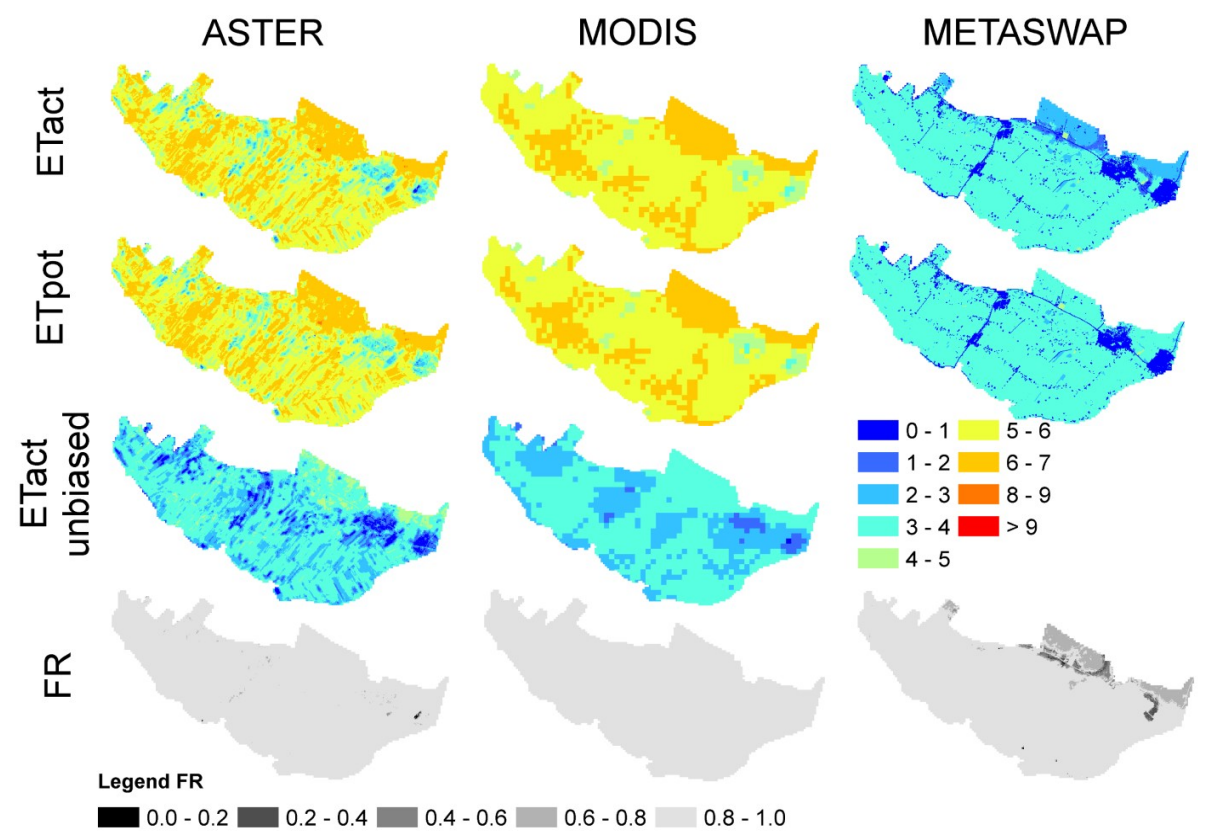

Fig. 3. Spatial plot of $\mathrm{ET}_{\text {act }}$ and $\mathrm{ET}_{\text {pot }}\left[\mathrm{mm} \mathrm{d}^{-1}\right]$ as derived by SEBAL from ASTER and MODIS images and by MetaSWAP as well as the bias corrected $\mathrm{ET}_{\text {act }}$ SEBAL images and $F R$ for 8 June 2006.

To investigate whether remotely sensed daily $\mathrm{ET}_{\text {act }}$ can improve our hydrological model, we use both ASTER (Advanced Spaceborne Thermal Emission and Reflection radiometer) and MODIS (MODerate resolution Imaging Spectroradiometer) satellite measurements of summer 2006 in association with the Surface Energy Balance Algorithm for Land (SEBAL). For 8 June 2006 and 17 July we have both an ASTER and MODIS image of the study area that have a spatial resolution of respectively $15 \mathrm{~m} \times 15 \mathrm{~m}$ and $250 \mathrm{~m} \times 250 \mathrm{~m}$.

SEBAL is based on the surface energy balance;

$R_{\mathrm{n}}=G_{0}+H+\lambda \rho E$

In which $R_{\mathrm{n}}\left[\mathrm{W} \mathrm{m}^{-2}\right]$ is the net radiation; $G$ is the soil heat flux; $H\left[\mathrm{~W} \mathrm{~m}^{-2}\right]$ is the sensible heat flux and $\lambda E$ [W $\mathrm{m}^{-2}$ ] is the latent heat flux that is associated with the actual evapotranspiration $\left(\mathrm{ET}_{\mathrm{act}}\right)$ by the latent heat of vaporazition $(\lambda)$ and $\rho$ is the density of water $\left[\mathrm{kg} \mathrm{m}^{-3}\right]$. At satellite overpass, the instantaneous energy balance can be partly $\left(R_{\mathrm{n}}\right.$ and $\left.G_{0}\right)$ solved with satellite data and ground based meteorological data. The remaining problem is the division between the (instantaneous) sensible en latent heat flux. SEBAL computes the sensible heat using a so-called "self calibration" procedure. The temperature difference between the land surface and the atmosphere at reference level $(\Delta T)$ that is needed to match the value of $H$ at a given aerodynamic resistance is calculated. For the coldest pixel in the satellite image $\Delta T=0$. For the warmest pixel it is assumed that $H=R_{\mathrm{n}}-G_{0}$ and $\Delta T$ is solved iteratively using the Monin-Obukhov Similarity Theory (MOST). After that a linear $\Delta T-T_{\mathrm{S}}$ relationship ( $T_{\mathrm{S}}$ is surface temperature based on satellite image) is fitted which is thus image specific. For MOST the roughness length is needed. In this study that comes from a slightly modified roughness map of the Royal Netherlands Meteorological Institute. This map is based on the Dutch national land-cover database LGN which is the same land use map that is used for our hydrological model. SEBAL assumes that the instantaneous evaporative fraction (i.e. the division between the sensible en latent heat flux) equals the daily evaporative fraction. With the daily net radiation, that is calculated for each satellite pixel, and the daily soil heat flux, that is calculated with a sinus relation, the daily actual evapotranspiration is calculated. The potential evapotranspiration is calculated by using a minimal stomatal resistance in the Penman-Monteith equation.

Figure 3 shows the spatial distribution of $\mathrm{ET}_{\mathrm{act}}, \mathrm{ET}_{\mathrm{pot}}$ and $F R$ for 8 June 2006 according to SEBAL (ASTER and MODIS) and MetaSWAP. Figure 4 shows the same for 17 July 2006. For both days SEBAL shows overall higher values of $\mathrm{ET}_{\text {act }}$ and $\mathrm{ET}_{\mathrm{pot}}$ than MetaSWAP. We comment on that in Sect. 4.2

For 8 June both SEBAL and MetaSWAP show little to no evapotranspiration reduction (high $F R$ value), except for MetaSWAP in the northeastern part of the study area. The spatial variation of $\mathrm{ET}_{\mathrm{pot}, \mathrm{m}}$ is due to the difference in crop factors. For major part of the study area (at least 80\%) $\mathrm{ET}_{\text {pot, } \mathrm{m}}$ is equal to $\mathrm{ET}_{\text {ref }}$, because the crop factor is 1.0. The built-up areas are clearly distinguishable, which is caused by the fact that built-up areas have a very low "crop factor" (0.05). The ASTER image reveals more spatial variation than 


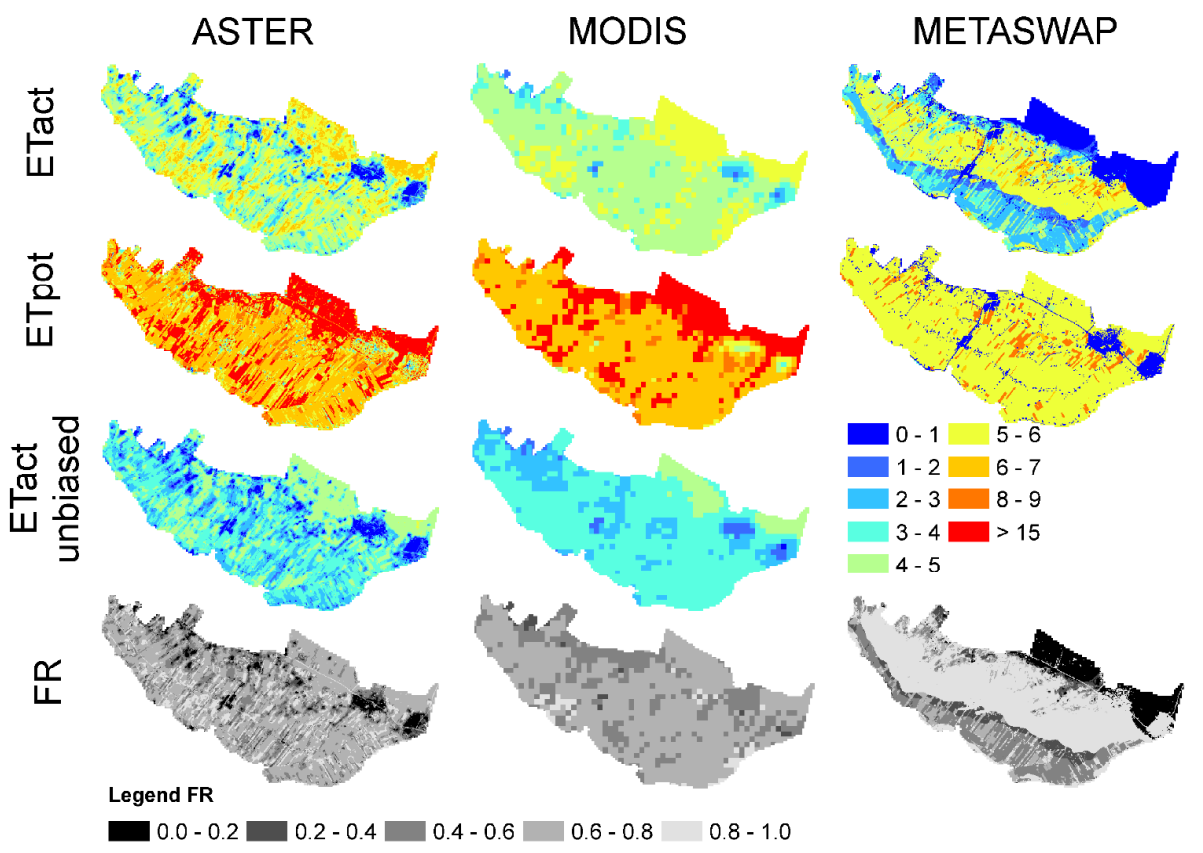

Fig. 4. Same as Fig. 2 but for 17 July 2006.

the MODIS image, which is due to its higher spatial variation. In both the ASTER and MODIS image, areas with forest and built-up areas are recognizable as areas with a relatively high and respectively low $\mathrm{ET}_{\text {pot }}$ value.

For 17 July both SEBAL and MetaSWAP show evapotranspiration reduction within the area, but their spatial distribution differs. MetaSWAP shows a high spatial variability in $\mathrm{ET}_{\text {act }}$ and the pattern resembles the soil type map (Fig. 1). In the northeast, the area at the high elevation with coarse sand and forest, $\mathrm{ET}_{\text {act }}$ is very low, even zero at some places. In the middle part there is hardly any evapotranspiration reduction, and in the southeastern part there is again evapotranspiration reduction. The $\mathrm{ET}_{\text {pot }}$ within MetaSWAP shows hardly any spatial variation, because the major part has the same crop factor, except for areas with maize, which have a crop factor of 1.3 that time of year (was 1.0 on 8 June) and again the built-up areas with a "crop factor" of 0.05 . In contrast to MetaSWAP, where there are clearly 3 regions, SEBAL shows more an overall evapotranspiration reduction. Both in the ASTER and MODIS images, built-up areas are recognizable as areas with a relatively low $\mathrm{ET}_{\text {act }}$.

\subsection{Soil moisture}

At 5 locations within the study area we measured soil moisture (Fig. 1b: SK, SZ, GD, WL and LB). The soil moisture locations were selected such that they lie within different soil types. At each location we measured soil moisture at 5 depths: $5,10,15,30$ and $50 \mathrm{~cm}$ below surface. Measurements were done using $20 \mathrm{~cm}$ ECH2O probes (EC-20), which use the capacitance technique (Bogena et al, 2007). Czarnomski et al. (2005) concluded that the EC-20 performed nearly as well as a TDR probe in a field experiment. All measurements were duplex with $\sim 1 \mathrm{~m}$ horizontal distance between the sensors. The output of our ECH2O sensors, volumetric moisture content $\left(\mathrm{VMC}\left[\mathrm{cm}^{3} \mathrm{~cm}^{-3}\right]\right)$, was measured with a temporal resolution of $5 \mathrm{~min}$. For each location we performed a calibration with observed VMC.

Figure 5 shows for all soil moisture measurement locations (see Fig. 1) the measured and modeled volumetric moisture content at the 5 different depths. According to the measurements at location SK the upper layers $(5$ and $15 \mathrm{~cm}$ ) are modeled too wet; 30 and $50 \mathrm{~cm}$ are modeled well and $70 \mathrm{~cm}$ is again too wet. However, we experienced during fieldwork that these data should be used carefully. Besides the fact that the measurements are done in heavy clay, which can lead to significant attenuation effects (Bogena et al., 2007), we observed clay cracks that were formed in these soils during severe drought. For location SZ, the model is wetter than the measurements at all depths. The dynamics of the measurements are however modeled well for the depths 5 and $15 \mathrm{~cm}$. In the deeper layers the measurements show much less dynamics than the model shows. For location GD the model represents the measurements quite well during the wet periods. However during drying out of the soil the model remains too wet. At location WL the model is too wet, except for the period in July where the modeled soil moisture at 5 and $15 \mathrm{~cm}$ is modeled dryer than was measured. In the forest, at location LB, the model is too dry for the upper layers. At 50 and $70 \mathrm{~cm}$ the model is slightly too wet, except for the 

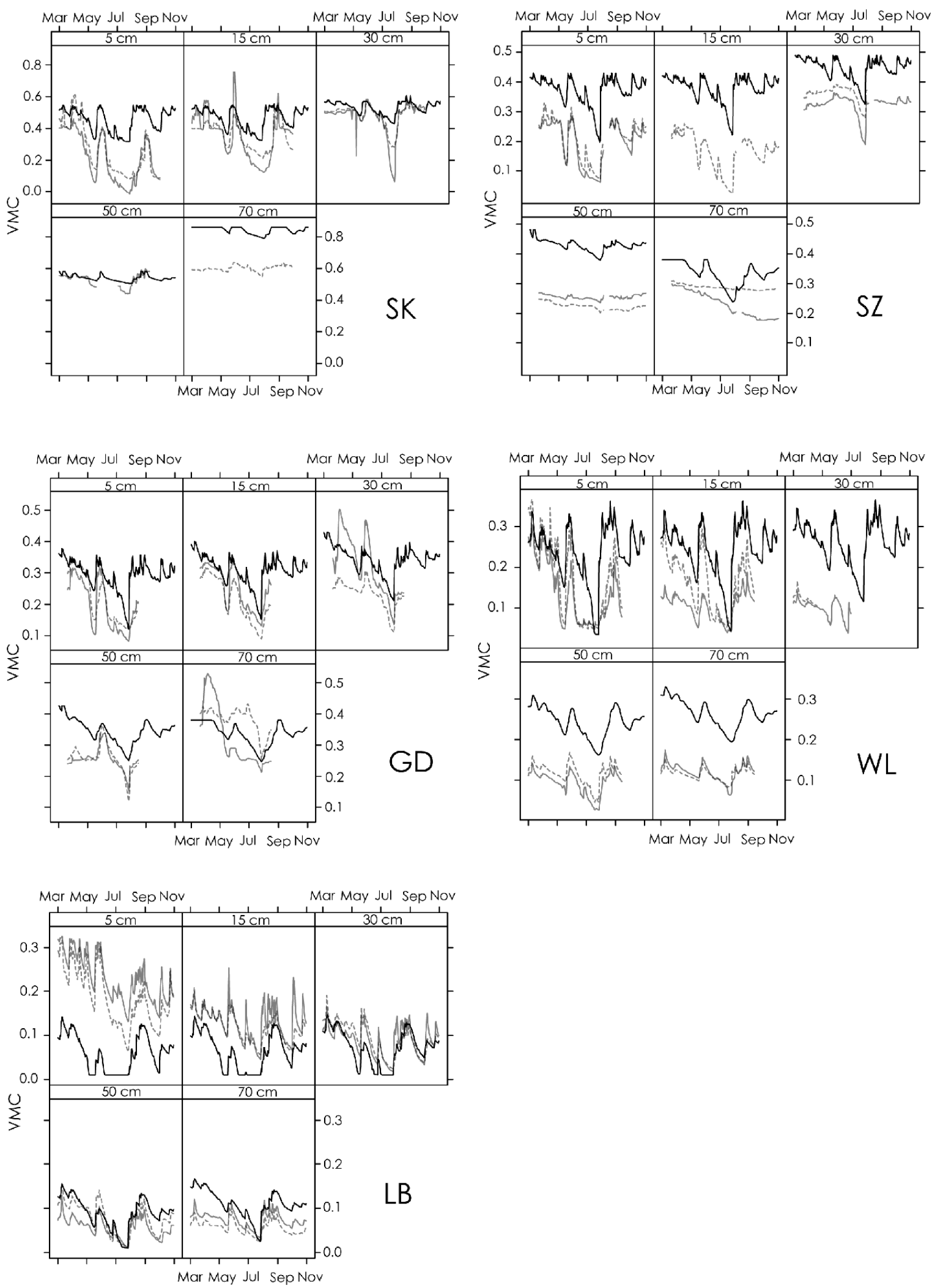

Fig. 5. Timeseries of VMC $\left[\mathrm{cm}^{3} \mathrm{~cm}^{-3}\right]$ per measurement location and per depth according to MetaSWAP (black solid line) and measurements (left side of pitch: grey solid lines, right side of pitch: grey dotted line). 


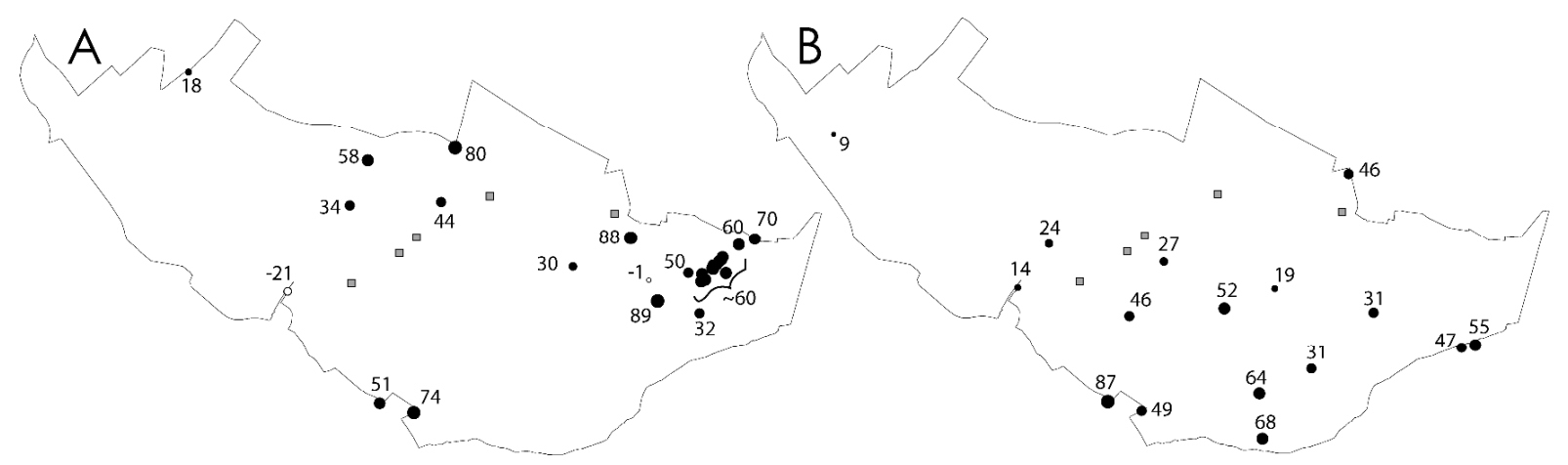

Fig. 6. Bias in phreatic (A) and confined (B) groundwater during 2001-2006 [cm].

dry period. It must be mentioned that especially the upper layer of LB contains a lot of organic material, which can decrease the accuracy of measurement considerably (Bogena et al., 2007).

\subsection{Groundwater}

Our groundwater model has constant head boundaries, which are the output of a larger model (from which this model was cut) after it was run for 5 years (2001-2006). The results of this 5 years model run are compared with measurements from observation wells within the study area, of which most of them are measured twice a month. Figure 6 shows bubble plots of the bias (mean difference between model and measurement) in $\mathrm{cm}$ for respectively the phreatic and confined groundwater level. Positive bias values, meaning the model is too wet, are indicated as black dots, negative bias values (model too dry) are indicated as white dots. Figure 6 shows that the majority of the dots is black, indicating that the modeled groundwater level is too high.

\section{Data assimilation}

\subsection{Method}

The data assimilation method we used for this study is very comparable with the method used in a previous study (Schuurmans et al., 2003). However for this study we have more data available to parameterize the statistical correction (Eq. 3). Each day a satellite image is available we have information about $\mathrm{ET}_{\text {act }}$ from both MetaSWAP (our hydrological model, see Sect. 3.1) and SEBAL (satellite based, see Sect. 3.3). We call this respectively $\mathrm{ET}_{\mathrm{act}, \mathrm{m}}$ and $\mathrm{ET}_{\mathrm{act}, \mathrm{s}}$ from now on. If we know the standard error of the MetaSWAP and SEBAL based $\mathrm{ET}_{\mathrm{act}}$ (resp. $\mathrm{SE}_{\mathrm{ET}_{\mathrm{act}, \mathrm{m}}}$ and $\mathrm{SE}_{\mathrm{ET}_{\mathrm{act}, \mathrm{s}} \text { ), we can }}$ make the following statistical correction of $\mathrm{ET}_{\mathrm{act}}$ per model node that gives us a new, updated value of $\mathrm{ET}_{\mathrm{act}}\left(\mathrm{ET}_{\mathrm{act}, \mathrm{new}}\right)$. With $\mathrm{ET}_{\text {act,new }}$ we prescribe per SVAT-unit a new FR (Eq. 1 and Fig. 2) and update the pressure head of the root zone in MetaSWAP.

$$
\mathrm{ET}_{\mathrm{act}, \mathrm{new}}=\mathrm{ET}_{\mathrm{act}, \mathrm{m}}+\frac{S E_{\mathrm{ET}_{\mathrm{act}, \mathrm{m}}}^{2}}{S E_{\mathrm{ET}_{\mathrm{act}, \mathrm{m}}}^{2}+S E_{\mathrm{ET}_{\mathrm{act}, \mathrm{s}}}^{2}}
$$

$$
\cdot\left(\underset{\mathrm{ET}_{\mathrm{act}, \mathrm{s}}^{\sim \sim \sim \sim}}{\sim \mathrm{ET}_{\mathrm{act}, \mathrm{m}}}\right)
$$

The statistical correction weighs $\mathrm{ET}_{\mathrm{act}, \mathrm{m}}$ and $\mathrm{ET}_{\mathrm{act}, \mathrm{s}}$ based on their confidence; if the standard error of $\mathrm{ET}_{\mathrm{act}, \mathrm{m}}$ is high the updated value $\mathrm{ET}_{\mathrm{act} \text {,new }}$ will tend to $\mathrm{ET}_{\mathrm{act}, \mathrm{s}}$ and vice versa. We hereby assume that (i) $\mathrm{ET}_{\mathrm{act}, \mathrm{m}}$ is unbiased and (ii) the error in $\mathrm{ET}_{\mathrm{act}, \mathrm{m}}$ is temporally variable but its variance is constant in time.

MetaSWAP and SEBAL use different methods to determine $\mathrm{ET}_{\text {pot }}$, the first is based on Makkink the latter on Penman-Monteith (Allen et al., 1998). We found that $\mathrm{ET}_{\text {pot,s }}\left(\mathrm{ET}_{\text {pot }}\right.$ from SEBAL) is overall higher than $\mathrm{ET}_{\text {pot, } \mathrm{m}}$

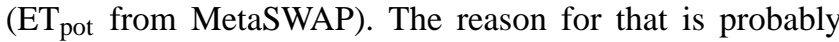
due to the fact that Makkink mainly depends on radiation whereas Penman-Monteith also takes into account the aerodynamic term (the wind speed as well as the vapour pressure deficit), see Sect. 3.3. Droogers (2009) shows with daily data from 1998-2007 that Makkink reference evapotranspiration never exceeds $6 \mathrm{~mm} \mathrm{~d}^{-1}$ in The Netherlands whereas Penman-Montheith reference evapotranspiration can be up to $8 \mathrm{~mm} \mathrm{~d}^{-1}$ for the same days. Although we realize that $\mathrm{ET}_{\text {pot, }}$ may be more realistic than $\mathrm{ET}_{\text {pot, } \mathrm{m}}$ we are interested in the reduction factor with which we want to update the modeled soil moisture. The values of $\mathrm{ET}_{\mathrm{act}, \mathrm{s}}$ should therefore be in the range of the model $\left(\mathrm{ET}_{\mathrm{act}, \mathrm{m}}\right)$. To achieve that we made a "bias" correction (Eq. 4), assuming that the spatial variability of evapotranspiration reduction ( $F R$, Eq. 1) shown by SEBAL is correct but the value of $\mathrm{ET}_{\text {pot, } \mathrm{s}}$ is biased. In Eq. (4) $\overline{\mathrm{ET}_{\text {pot, } \mathrm{m}}}$ and $\overline{\mathrm{ET}_{\text {pot, } \mathrm{s}}}$ are the spatial mean $\mathrm{ET}_{\text {pot, } \mathrm{m}}$ and $\mathrm{ET}_{\text {pot,s. }}$. For 8 June we applied a bias correction of 2.5 and $2.74 \mathrm{~mm} \mathrm{~d}^{-1}$ for respectively ASTER and MODIS. For 17 
July we applied a bias correction of 1.96 and $2.09 \mathrm{~mm} \mathrm{~d}^{-1}$ for respectively ASTER and MODIS.

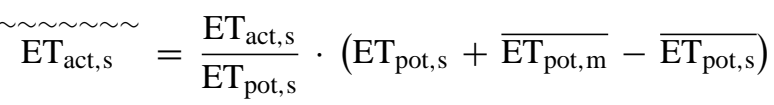

\subsection{Parameterization}

To estimate $S E_{\mathrm{ET}_{\text {act, } \mathrm{m}}}$ we calculated $\mathrm{ET}_{\text {act }}$ according to MetaSWAP for the situation that we have the measured instead of the modeled VMC. Doing so we assume that the model concept of calculating $\mathrm{ET}_{\text {act }}$ is correct and the measured soil moisture is the truth. In this case we can estimate $S E_{\mathrm{ET}_{\text {act, } \mathrm{m}}}$ at five locations, as we have five soil moisture measurement locations. At each location the VMC measurements are duplex at five different depths $(5,15,30,50$, $70 \mathrm{~cm}$ ). For each depth we took the mean of the duplex measurements. Because the model uses pressure heads instead VMC, we used the inverse Van Genuchten Equation (Van Genuchten, 1980), that calculates analytically the pressure head from VMC. We assume a uniform root distribution within the root zone and using the Feddes curve (Fig. 2) and Eq. (1) to derive a time series of $\mathrm{ET}_{\text {act }}$ at each depth (Eq. 5). At the measurement locations, we only have two different root zone depths: $30 \mathrm{~cm}$ (SK, SZ, GD, WL) and $100 \mathrm{~cm}$ (LB).

$\mathrm{ET}_{\mathrm{act}, \mathrm{rz}}=$

$\int \frac{1}{6} \cdot \mathrm{ET}_{\mathrm{act}, 5 \mathrm{~cm}}+\frac{2}{6} \cdot \mathrm{ET}_{\mathrm{act}, 15 \mathrm{~cm}}+\frac{3}{6} \cdot \mathrm{ET}_{\mathrm{act}, 30 \mathrm{~cm}}$ for $\mathrm{rz}=30 \mathrm{~cm}$

$\left\{\begin{array}{l}\frac{1}{20} \cdot \mathrm{ET}_{\text {act, }, 5 \mathrm{~cm}}+\frac{2}{20} \cdot \mathrm{ET}_{\text {act, }, 15 \mathrm{~cm}}+\frac{3}{20} \cdot \mathrm{ET}_{\text {act, }, 30 \mathrm{~cm}}+\frac{4}{20} \cdot \mathrm{ET}_{\text {act, }, 50 \mathrm{~cm}}+\frac{10}{20} \cdot \mathrm{ET}_{\text {act, } 70 \mathrm{~cm}} \text { for } \mathrm{rz}=100 \mathrm{~cm}\end{array}\right.$

With $\mathrm{ET}_{\mathrm{act}, \mathrm{rz}}$ we can determine the error in $\mathrm{ET}_{\mathrm{act}, \mathrm{m}}\left(\mathrm{ET}_{\mathrm{act}, \mathrm{m}^{-}}\right.$ $\mathrm{ET}_{\mathrm{act}, \mathrm{rz}}$ ) for each soil moisture measurement location and

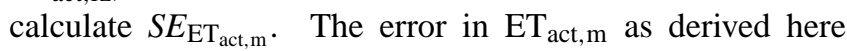
is a conservative estimation of the model error because the possible measurement error of the soil moisture probes are counted as model error. Using this method we assume that the relation between soil moisture and $\mathrm{ET}_{\text {act }}$ given by the Feddes curve is correct but the modelled soil moisture is biased. A better method to estimate $S E_{\mathrm{ET}_{\text {act, m }}}$ would be to determine the change in soil water storage. Measurements of VMC are not enough because assumptions on the percolation term are needed. Lysimeters could be an alternative.

We state that the derived $S E_{\mathrm{ET}_{\mathrm{act}, \mathrm{m}}}$ at each location is representative for a part of the model area (error zone), as we have only five measurement locations but want to apply the statistical correction method to all SVAT-units. Table 1 shows to which error zone the different soil types in the study area are classified, which is based on the soil physical parameters. Table 2 shows the values of $S E_{\mathrm{ET}_{\mathrm{act}, \mathrm{m}}}$, as well as the error zones for which the five measurement locations are representative.

We state that SEBAL images provide insight in the spatial pattern of $\mathrm{ET}_{\mathrm{act}}$ within an area and assume $S E_{\mathrm{ET}_{\mathrm{act}, \mathrm{s}}}$ to be spatially uniform. Because we had no measurements of $\mathrm{ET}_{\mathrm{act}}$ within the study area it was not possible to calculate the $S E_{\mathrm{ET}_{\mathrm{act}, \mathrm{s}}}$ ourselves. However, data is available (source: www.waterwatch.nl) of a validation study in The Netherlands where in 1995 weekly ET $_{\text {act }}$ measurements of SEBAL
Table 2. Standard error of the $\mathrm{ET}_{\mathrm{act}} \mathrm{m}$ per measurement location and the related error zone (Fig. 1).

\begin{tabular}{lccccc}
\hline & SK & SZ & GD & WL & LB \\
\hline Error zone & 1 & 2 & 3 & 4 & 5 \\
$\mathrm{SE}_{\mathrm{ET}_{\text {act,m }}\left(\mathrm{mm} \mathrm{d}^{-1}\right)} 0.69$ & 0.78 & $0.94 \mathrm{e}-02$ & 0.41 & 0.69 \\
\hline
\end{tabular}

are compared to eddy-correlation measurements (306 measurements). This study shows a value for $S E_{\mathrm{ET}_{\mathrm{act}, \mathrm{s}}}$ of 1.5$1.9 \mathrm{~mm}$ week $^{-1}$. Assuming this error is random, and choosing the upper bound, we get $S E_{\mathrm{ET}_{\mathrm{act}, \mathrm{s}}}=\frac{1.9}{\sqrt{7}}=0.72 \mathrm{~mm} \mathrm{day}^{-1}$.

We now have the values for $S E_{\mathrm{ET}_{\text {act,m }}}$ and $S E_{\mathrm{ET}_{\text {act, }}}$ with which we can calculate $\mathrm{ET}_{\text {act, new }}$ for each modelnode (Eq. 3). Using $\mathrm{ET}_{\text {pot, } \mathrm{m}}$ (model based $\mathrm{ET}_{\text {pot }}$ ) we prescribe per SVATunit a new $F R$ (Eq. 1 and Fig. 2) and update the pressure head of the root zone in MetaSWAP. Four different scenarios are possible:

- scen 1: $F R_{\mathrm{m}}=1$ and $F R_{\text {new }}>=1:$ no update of soil moisture because there was and is no evapotranspiration reduction;

- scen 2: $F R_{\mathrm{m}}<1$ and $F R_{\text {new }}>=1$ : soil becomes wetter. In contrast to our previous study (Schuurmans et al., 2003) we do not take the reduction point $\left(h_{3}\right)$ but make a linear interpolation between $h_{2}$ and $h_{3}$ of the Feddes curve, based on the value of FRnew. If $F R_{\text {new }} \geq 15$ then the pressure head $(h)$ is set to $h_{2}$, if $F R_{\text {new }}=1, h$ is set to $h_{3}$ (reduction point);

- scen 3: $F R_{\mathrm{m}}=1$ and $F R_{\text {new }}<1$ : soil becomes dryer;

- scen 4: $F R_{\mathrm{m}}<1$ and $F R_{\text {new }}<1$ : an update of $h$ takes place somewhere between $h_{3}$ and $h_{4}$ of the Feddes curve, meaning the soil becomes either dryer or wetter.

\section{Results and discussion}

\subsection{Updated soil moisture results}

Figure 7 shows the spatial difference of the root zone storage between the unperturbed and updated MetaSWAP run using either ASTER or MODIS images of 8 June 2006 and 17 July 2006. The difference is plotted 1 day after update, 10 days after update and at the end of the modeling period (1 November 2006). Negative values (indicated with blue) mean that the root zone storage in the updated model run is higher than in the unperturbed run, so MetaSWAP becomes wetter after update. The opposite is true for the positive difference values, which are indicated with red.

For 8 June the overall modeled soil moisture in the lower area decreased after implementation of our data assimilation 


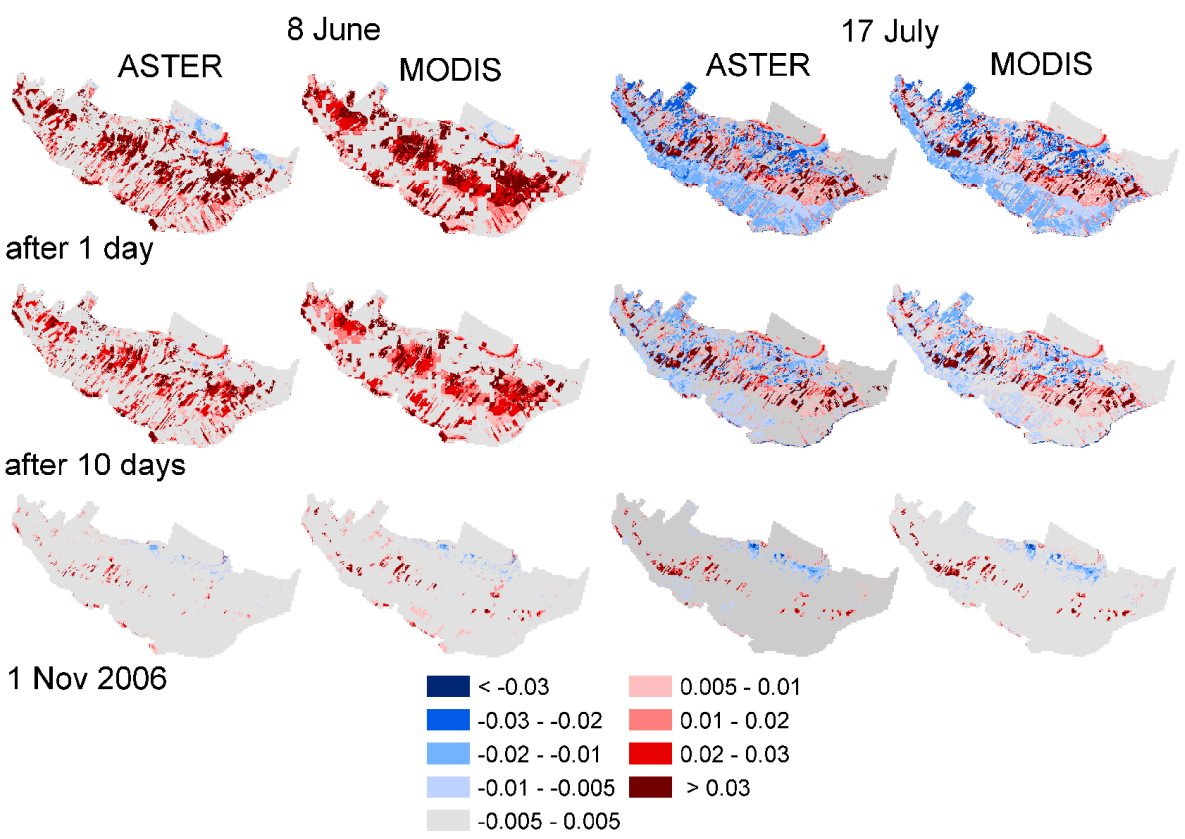

Fig. 7. Spatial difference of the root zone storage $[\mathrm{m}]$ between unperturbed and updated model run using either ASTER or MODIS images of 8 June and 17 July.

method, especially within the soil units 19 and 12 . Considering the time series of measured and modeled soil moisture at the 5 measurement locations (Fig. 5) this seems to be realistic. However, the 5 measurement locations are point measurements and it is hard to identify their representativeness over the whole study area. In the higher region of the study area the modeled soil moisture is slightly increased. 17 July is in particular an interesting day as it shows evapotranspiration reduction for both MetaSWAP and SEBAL, but with a different spatial distribution. This day three different regions in the spatial pattern of the differences between MetaSWAP and SEBAL can be distinguished:

- region 1: the northeastern part where

$$
\mathrm{ET}_{\mathrm{act}, \mathrm{s}}>\mathrm{ET}_{\mathrm{act}, \mathrm{m}}
$$

- region 2: the middle part where $\mathrm{ET}_{\mathrm{act}, \mathrm{m}}>\stackrel{\sim \sim \sim \sim \sim \sim \sim}{\mathrm{ET}_{\mathrm{act}, \mathrm{s}}}$;

- region 3: the southwest part where

$$
\mathrm{ET}_{\mathrm{act}, \mathrm{s}}>\mathrm{ET}_{\mathrm{act}, \mathrm{m}} \text {. }
$$

In region 1 both SEBAL and MetaSWAP show evapotranspiration reduction but the amount of reduction showed by MetaSWAP is extremely high. Nevertheless Fig. 7 hardly shows an increase in the soil moisture content. This is due to the fact that $\mathrm{ET}_{\mathrm{act}, \text { new }}$ is a linear combination of $\mathrm{ET}_{\mathrm{act}, \mathrm{m}}$ and unbiased $\mathrm{ET}_{\mathrm{act}, \mathrm{s}}$. Because $\mathrm{ET}_{\mathrm{act}, \mathrm{m}}$ is extremely low, $\mathrm{ET}_{\text {act,new }}$ is also low which means that the increase in soil moisture is only marginal. In region 2 soil moisture is reduced, which seems plausible considering the modeled and measured soil moisture (Fig. 5). In region 3 the modeled soil moisture is increased. Both SEBAL and MetaSWAP show evapotranspiration reduction but the SEBAL based reduction is lower. This is the most difficult area to decide whether this is plausible or not. The soil moisture measurement location SK is situated at the border of soil unit 19. This is an area with heavy clay that showed severe clay cracks during this period that in reality could reduce the evapotranspiration of grass (that roots mainly in the upper part). Besides, the soil moisture measurements of the upper layer should be handled with care.

\subsection{Discussion}

In areas with forest MetaSWAP shows for both days severe evapotranspiration reduction in contrast to SEBAL. It could be discussed whether SEBAL maybe overestimates $\mathrm{ET}_{\text {act }}$ in areas with forest. However, increasing the crop factor in MetaSWAP is no solution for solving the evapotranspiration reduction in the northeastern part of the study area. We found that increasing the crop factor of forest only led to a faster dry out of the soil and thus lower $\mathrm{ET}_{\text {act }}$ values in an earlier stage. This prevented us from increasing the crop factor of forest.

We hypothesize that the big difference between $\stackrel{\sim \sim \sim \sim \sim \sim}{\mathrm{ET}_{\mathrm{act}, \mathrm{s}}}$ and $\mathrm{ET}_{\mathrm{act}, \mathrm{m}}$ in the northeast region of the study area (forest dominated, groundwater level is $\sim 60 \mathrm{~m}$ below surface) is caused by a conceptual error in MetaSWAP. Evapotranspiration in forests is a complex process, mainly because of changes in root water uptake under stress. This has been the subject for many studies. The essence is that trees have 
special ways of water conservation allowing them to keep evapotranspiration going during dry spells. Trees, but also some small plants like dandelion, radish and carrot, use water in a much more complex way than is implemented in this model, the so-called "hydraulic redistribution" or "hydraulic lift" (Warren et al., 2007; Lee et al., 2005; Dawson, 1996; Caldwell et al., 1998). This was also concluded by Feddes et al. (2001). Deep rooted plants take in water from deeper moist soil layers and exude that water during the night into the drier upper soil layers. Tap roots (a straight tapering root that grows vertically down) can also transfer rainwater from the surface to reservoirs deep underground and redistribute water upwards after the rains. Lee et al. (2005) found in Brazil that trees could store $10 \%$ of the annual precipitation as deep as $13 \mathrm{~m}$. In some cases taproots can reach down more than 100 times the height of the plant above ground.

Despite the big difference between $\stackrel{\sim \sim \sim \sim \sim \sim}{\mathrm{ET}_{\mathrm{act}, \mathrm{s}}}$ and $\mathrm{ET}_{\mathrm{act}, \mathrm{m}}$ in the northeastern part of the study area, the soil moisture content of the root zone becomes hardly any higher after data assimilation. It should therefore be questioned (i) whether $\mathrm{ET}_{\text {act }}$ is a good variable to update the soil moisture content of the topsoil because in reality the evaporation process of forests is much more complex that involves soil moisture in deeper layers and (ii) a different, non-linear assimilation method should be applied.

\section{Conclusions and outlook}

The results of this study show that with the satellite based $\mathrm{ET}_{\mathrm{act}}$ images we can indicate areas with structural errors in our hydrological model. The first error is concept related: fixed root zone modelling is not correct for areas with deep groundwater tables. The second is flux related: for the lower areas too much seepage is calculated due to the geohydrological parameterization. In this case study, despite the lower spatial resolution of the MODIS images, they appeared just as useful as the ASTER images.

We showed that assimilation of $\mathrm{ET}_{\text {act }}$ resulted in a spatial pattern of soil moisture adjustment that we consider to be realistic, apart from the area with forest and deep groundwater level. However, due to a lack of other spatiallydistributed validation data it is hard to prove this. The major weakness of the assimilation scheme is the parameterization of the standard error of $\mathrm{ET}_{\text {act }}$ from the hydrological model (MetaSWAP) and SEBAL. Better insight in $S E_{\mathrm{ET}_{\text {act, }}}$ could be given by using ground based $\mathrm{ET}_{\text {act }}$ measurements (e.g. eddy-correlation system; scintillometer or lysimeter). The assumption of a spatial uniform $S E_{\mathrm{ET}_{\mathrm{act}, \mathrm{s}}}$ might also be incorrect as it is likely to be a structural component as well, mainly in forest. Due to a strong roughness, the super temperature signature of forest water stress is very low and so, more difficult to detect for SEBAL.

Only during periods with evapotranspiration reduction, there is a linkage between soil moisture and $\mathrm{ET}_{\mathrm{act}}$, which makes it useful to use satellite based $\mathrm{ET}_{\mathrm{act}}$ in order to improve the accuracy of soil moisture as calculated by our hydrological model. Besides, the temporal resolution of satellite based $\mathrm{ET}_{\text {act }}$ is not guaranteed to be the same as the return period of the (polar orbiting) satellite because of cloud conditions. This makes a regular online adjustment of modeled soil moisture content not feasible.

Data assimilation updates state variables of the hydrological model but does not solve the underlying cause of error in the hydrological model that leads to the difference between modeled and remotely sensed $\mathrm{ET}_{\text {act }}$. Data assimilation should therefore not be considered as a replacement for model calibration or solution for structural model error.

Finally, we believe that a different land-plant-atmosphere interaction concept should be tested and implemented in MetaSWAP, as was also recognized by Feddes et al. (2001).

Acknowledgements. The authors want to thank Wouten Meijninger and Wim Bastiaanssen from WaterWatch for applying SEBAL to the satellite images as well as for their advice, Paul van Walsum from Alterra for his support with MetaSWAP and The Royal Netherlands Meteorological Institute (KNMI) for their rainfall and evapotranspiration data. Inger de Groot and Chris Roosendaal from Utrecht University are thanked for their support during field data collection. The reviewers are thanked for their comments that helped us to improve this article.

Edited by: P. van Oevelen

\section{References}

Allen, R. G., Pereira, L. S., Raes, D., and Smith, M.: Crop evapotranspiration: Guidelines for computing crop water requirements, FAO Irrigation and drainage paper 56., FAO-Food and agriculture Organization of the United Nations, Rome, 1998.

Allen, R. G., Bastiaanssen, W. G. M., Tasumi, M., and Morse, A.: Evapotranspiration on the watershed scale using the SEBAL model and Landsat images, ASAE Meeting Presentation, paper number 01-2224, Sacramento, California, USA, 30 July-1 August, 2001.

Bastiaanssen, W. G. M.: Regionalization of surface flux densities and moisture indicators in composite terrain, A remote sensing approach under clear skies in Mediterranean climates, Ph.D. thesis, Landbouwuniversiteit Wageningen, Wageningen, 1995.

Bastiaanssen, W. G. M., Noordman, E. J. M., Pelgrum, H., Davids, G., Thoreson, B. P., and Allen, R. G.: SEBAL model with remotely sensed data to improve water-resources management under actual field conditions, J. Irrig. Drain. E-ASCE, 131, 85-93, 2005.

Berendsen, H. J. A. and Stouthamer, E.: Late Weichselian and Holocene palaeogeography of the Rhine-Meuse delta, The Netherlands, Palaeogeogr. Palaeocl., 161(3-4), 311-335, 2000.

Bergström, S. and Graham, L. P.: On the scale problem in hydrological modelling, J. Hydrol., 211, 253-265, 1998.

Bogena, H. R., Huisman, J. A., Oberdörster, C., and Vereecken, H.: Evaluation of a low-cost soil water content sensor for wireless network applications, J. Hydrol., 344, 32-42, 2007. 
Busschers, F. S., Kasse, C., and Van Balen, R. T.: Late Pleistocene evolution of the Rhine-Meuse system in the Southern North Sea basin: imprints of climate change, sea-level oscillation and glacio-isostacy, Quaternary Sci. Rev., 26, 3216-3248, 2007.

Caldwell, M. M., Dawson, T. E., and Richards, J.: Hydraulic lift: consequences of water efflux from the roots of plants, Oecologia, 113, 151-161, 1998.

Czarnomski, N. M., Moore, G. W., Pypker, T. G., Licata, J., and Bond, B. J.: Precision and accuracy of three alternative instruments for measuring soil water content in two forest soils of the Pacific Northwest, Can. J. Forest Res., 35, 1867-1876, 2005.

Dawson, T. E.: Determining water use by trees and forests from isotopic, energy balance and transpiration analyses: The role of tree size and hydraulic lift, Tree Physiol., 16, 263-272, 1996.

De Bruin, H. A. R.: From Penman to Makkink (In Dutch), Proc. And Inf. Vol. 39, TNO Committee of Hydrological Research, CHO-TNO The Hague, The Netherlands, 5-31, 1987.

De Wit, A. J. W. and Clevers, J. G. P. W.: Efficiency and accuracy of per-field classifcation for operational crop mapping, Int. J. Remote Sens., 25(20), 4091-4112, 2004.

Droogers, P.: Improving actual evapotranspiration for strategic watermanagement: definition study (in Dutch), STOWA rapport 2009-11, ISBN: 978.90.5773.428.1, STOWA, Utrecht, The Netherlands, 2009.

Feddes, R. A.: Crop factors in relation to Makkink reference-crop evapotranspiration, Comm. Hydrol. Res. TNO, The Hague, Proc. and Inf. 39, 33-44, 1987.

Feddes, R. A., Kowalik, P. J., and Zaradny, H.: Simulation of field water use and crop yields, Simulation monographs, Pudoc, University of Wageningen, 1978.

Feddes, R. A., Hoff, H., Bruen, M., Dawson, T., de Rosnay, P., Dirmeyer, P., Jackson, R. B., Kabat, P., Kleidon, A., Lilly, A., and Pitman, A. J.: Modeling root water uptake in hydrological and climate models, B. Am. Meteorol. Soc., 82(12), 2797-2810, 2001.

Immerzeel, W. W. and Droogers, P.: Calibration of a distributed hydrological model based on satellite evapotranspiration, J. Hydrol., 349, 411-424, 2008.

Kustas, W. P. and Norman, J. M.: Use of remote sensing for evapotranspiration monitoring over land surfaces, Hydrolog. Sci. J. Journal Des Sciences Hydrologiques, 41, 495-516, 1996.

Lee, J. E., Oliveiria, R. S., Dawson, T. E., and Fung, I.: Root functioning modifies seasonal climate, P. Natl. Acad. Sci. USA, 102, 17576-17581, 2005.
Makkink, G. F.: Testing the Panman formula by means of lysimeters, J. Int. Water England, 11, 277-288, 1957.

McDonald, M. G. and Harbaugh, A. W.: A modular threedimensional finite-difference ground-water flow model, OpenFile Report 83-875, US Geological Survey, p.528, 1988.

Pipunic, R. C., Walker, J. P., and Western, A.: Assimilation of remotely sensed data for improved latent and sensible heat flux prediction: A comparative synthetic study, Remote Sens. Environ., 112, 1295-1305, 2008.

Schuurmans, J. M., Troch, P. A., Veldhuizen, A. A., Bastiaanssen, W. G. M., and Bierkens, M. F. P.: Assimilation of remotely sensed latent heat flux in a distributed hydrological model, Adv. Water Res., 26, 151-159, 2003.

Schuurmans, J. M., Bierkens, M. F. P., Pebesma, E. J., and Uijlenhoet, R.: Automatic prediction of high-resolution daily rainfall fields for multiple extents: the potential of operational radar, J. Hydrometeorol., 8, 1204-1224, 2007.

$\mathrm{Su}, \mathrm{Z}$.: The Surface Energy Balance System (SEBS) for estimation of turbulent heat fluxes, Hydrol. Earth Syst. Sci., 6, 85-100, doi:10.5194/hess-6-85-2002, 2002.

Van Dam, J. C.: Field-scale water flow and solute transport. SWAP model concepts, parameter estimation, and case studies, $\mathrm{PhD}$ thesis, Wageningen University, Wageningen, The Netherlands, p.167, 2000.

Van Genuchten, M. Th.: A closed-form Eq for predicting the hydraulic conductivity of unsaturated soils, Soil Sci. Soc. Am. J., 44, 892-898, 1980.

Van Oort, P. A. J., Bregt, A. K., de Bruin, S., and de Wit, A. J. W.: Spatial variability in classification accuracy of agricultural crops in the Dutch national land-cover database, Int. J. Geogr. Inf. Sci. 18, no. 6, September 2004, 611-626, 2004.

Van Walsum, P. E. V. and Groenendijk, P.: Quasi steady-state simulation of the unsaturated zone in groundwater modeling of lowland regions, Vadose Zone J., 7, 769-781, 2008.

Warren, J. M., Meinzer, F. C., Brooks, J. R., Domec, J. C., and Coulombe, R.: Hydraulic redistribution of soil water in two old-growth coniferous forests: quantifying patterns and controls, New Phytol., 173, 753-765, 2007.

Winter, T. C., Rosenberry, D. O., and Sturrock, A. M.: Evaluation of 11 Eqs for determining evaporation for a small lake in the North Central United States, Water Resour. Res., 31(4), 983-993, 1995.

Wösten, J. H. M., De Vries, F., Denneboom, J., and Van Holst, A. F.: Generalization and soil physical translation of the Dutch soil map, 1:250.000, on behalf of the PAWN-study, Report nr. 2055, Stichting voor Bodemkartering, Wageningen, 1988. 